\title{
Quality Evaluation and Structure Optimization of Tourism Landscape
}

\author{
Bo Liu \\ Wuchang University of Technology \\ Corresponding E-mail:164613497@qq.com
}

\begin{abstract}
Since the middle of the twentieth century, the mass tourism has been flourishing, tourism landscape has been got broad attention researched by all fields, human geography, landscape ecology and landscape architecture can play the discipline specialty, which can deepen the research of tourism landscape gradually. In this paper, it takes the evaluation of the quality of tourism landscape as the starting point, selecting Zhouzhuang as the research model, based on the quality of tourism landscape evaluation method to evaluate the quality of the landscape, putting forward the concept of quality structure optimization of tourism landscape.
\end{abstract}

Keywords: tourism landscape; quality evaluation; structure; optimization; validation factor.

\section{Introduction}

Tourism landscape has appeared a significant interdisciplinary and systematic trend, the researchers not only begin to break the boundaries of the original disciplines, but also begin to have a comprehensive study on the landscape subject, object and media systematically as well as in other methods to expand the study, so that the tourism landscape research can study from a single one to comprehensive one, from the phenomenon to mechanism. Quality evaluation of tourism resources is a measure of the aesthetic quality of the tourism landscape, the art of the object, the aesthetic features, historical value and cultural value, as well as the scarcity of scientific value, which can play a significant role in evaluating the special features.

\section{Overview of Tourism Landscape Quality Evaluation}

The word of "landscape" is used firstly as English in the Bible. Each field has different understanding towards the concept of landscape, namely the various fields have their own different views, as for landscape architecture, it defines the concept of landscape from the visual aesthetic level. The so called "landscape" is based on the understanding from the geography level, which is like the "ecosystem" or "community"; landscape is from "the analysis of forest landscape pattern", which is the combination of ecological system in landscape ecology. [1] Since scenery has the same feature with landscape, among them, the landscape has many levels, with the features of multi function and multi structure of the system, which is the most significant difference between the scenery. Relatively speaking, the meaning of landscape quality evaluation is is the evaluation of landscape visual quality.

\section{Method of Evaluating Tourism Landscape Quality}

Resource evaluation and landscape evaluation are two major fields of traditional tourism evaluation studies. The purpose of evaluating tourism resources is to identify the type of tourism resources, analyze the organization structure of tourism resources, so as to determine the value of tourism resources and evaluate the impact of tourism resources. From the perspective of method, the evaluation of tourism resources can be including two kinds, namely, qualitative evaluation and quantitative evaluation,[2] qualitative evaluation is good at grasping the overall and characteristic of tourism resources, evaluating tourism resources, as well as the aesthetic evaluation of tourism resources, moreover, the comprehensive evaluation of the tourism resources are widely used. The quantitative evaluation can improve the evaluation results of the tourism resources in more intuitive way through the construction of the index system. In recent years, the analytic hierarchy method,[3] comprehensive evaluation method,[4] and fuzzy mathematics method[5] and other quantitative 
methods have been widely used in the evaluation of tourism resources, which can promote the in-depth study of tourism resources evaluation.

In this paper, it takes the time attribute, spatial attribute and functional attribute as the second level evaluation indicator, so as to construct the evaluation index system of tourism landscape image, and the first level evaluation indicator of the evaluation index system is the quality of tourism landscape image, and the third level evaluation indicator is the sub-evaluation generated by the specific characteristics of the object.Taking Zhouzhuang as the object of study, according to the survey data, using the bottom-up approach, combined with the statistical analysis means to generate evaluation system of indicators and weights, so as to avoid the subjective thinking during the process of constructing the index system, this kind of elastic construction method of evaluation index system can enhance the flexibility and applicability of the tourism landscape image evaluation method, which can make it possible between different types of tourism landscape images. The relationship of the evaluation index of the tourism landscape image can be shown as follows, see Table 1:

Tab. 1 The attribution of indicator variables

\begin{tabular}{|c|c|c|}
\hline The first level indicator & The second level indicator & The third level indicator \\
\hline \multirow{9}{*}{$\begin{array}{c}\text { The quality of tourism } \\
\text { landscape (Q) }\end{array}$} & \multirow{4}{*}{$\begin{array}{l}\text { The functional attribute } \\
\text { (M) }\end{array}$} & The firms of entertainment $\left(\mathrm{M}_{1}\right)$ \\
\hline & & Accommodation conditions $\left(\mathrm{M}_{2}\right)$ \\
\hline & & Characteristic dining $\left(\mathrm{M}_{3}\right)$ \\
\hline & & Leisure facilities $\left(\mathrm{M}_{4}\right)$ \\
\hline & \multirow{3}{*}{ Time attribute $(\mathrm{T})$} & Historical monuments $\left(\mathrm{T}_{1}\right)$ \\
\hline & & Landmarks $\left(\mathrm{T}_{2}\right)$ \\
\hline & & The size of area $\left(\mathrm{S}_{1}\right)$ \\
\hline & \multirow{2}{*}{ Spatial attribute (S) } & Spatial structure $\left(\mathrm{S}_{2}\right)$ \\
\hline & & Internal integrity $\left(\mathrm{S}_{3}\right)$ \\
\hline
\end{tabular}

Firstly, the research adopts exploratory factor analysis result, then having the objective weights to the second level indicator, the following is the calculating method:

$W i=V i / \sum V$

Among them, $i=M, T, S$.

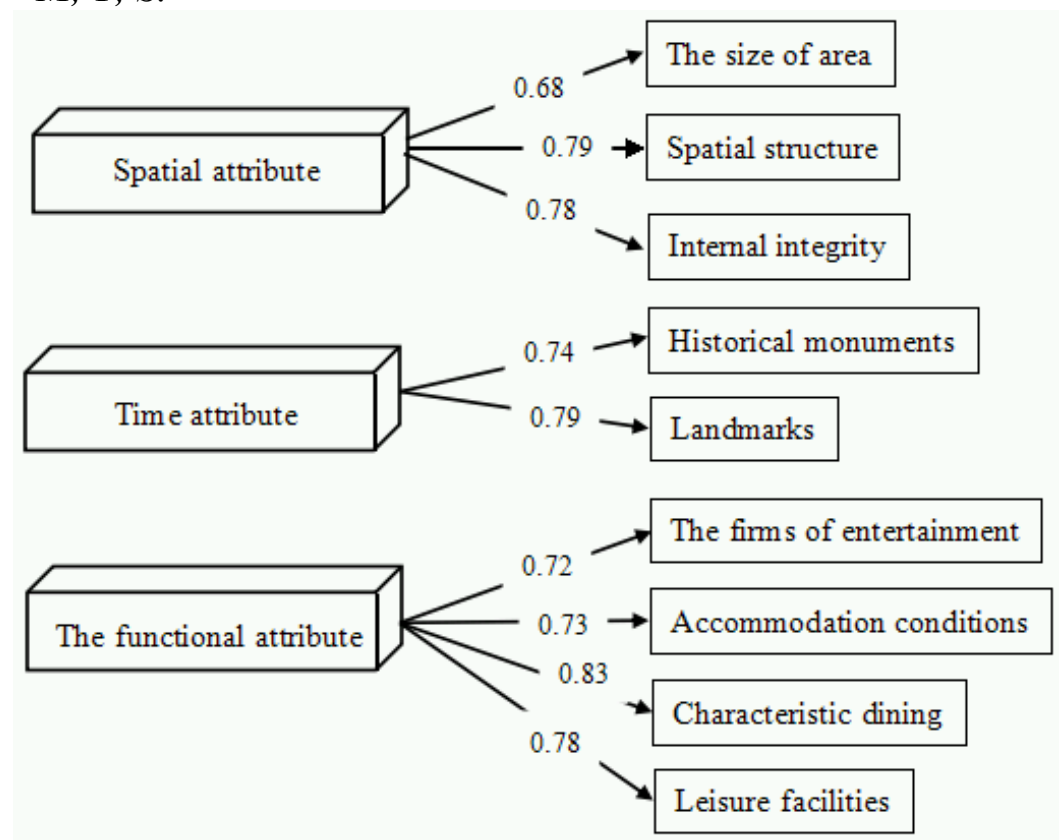

Fig. 2 Confirmatory factor analysis (Zhouzhuang) 
After calculating, the weight of these three second level indicators, namely, function, time and space are $0.59,0.29$ and 0.12 respectively.

Then the study adopts the structural equation model to verify the factor analysis, according to the latent variables (the second level indicator) and the observed variables (the third level indicator) with the path coefficient $(\gamma)$ to determine the weight of the third level indicator (see Fig. 1).

\section{Linear Model of Tourism Landscape Quality Evaluation}

In summary, when the single observation variable of the quality of the tourism landscape is $x i, j(i=$ $M, T, S ; j=1,2,3, \ldots)$, the linear model of the tourism landscape quality evaluation is:

$$
Y_{Q}=\sum_{i} \sum_{j=1}^{n} w_{i j} x_{i j}
$$

\subsection{Optimization of Tourism Landscape Quality Structure}

The image of tourism landscape is the interactive link between the object of tourism landscape and the main body of the tourist, and the evaluation of the tourism landscape image is an important aspect of the evaluation of the tourism landscape. In this paper, a kind of flexible evaluation index system of tourism landscape image is put forward, and the weight coefficient of index is generated by using the objective method from up to down. Besides, the linear evaluation on the tourism landscape image made by the index system, it can evaluate the coupling coordination degree of the tourism landscape image, which can be seen in Fig.3.

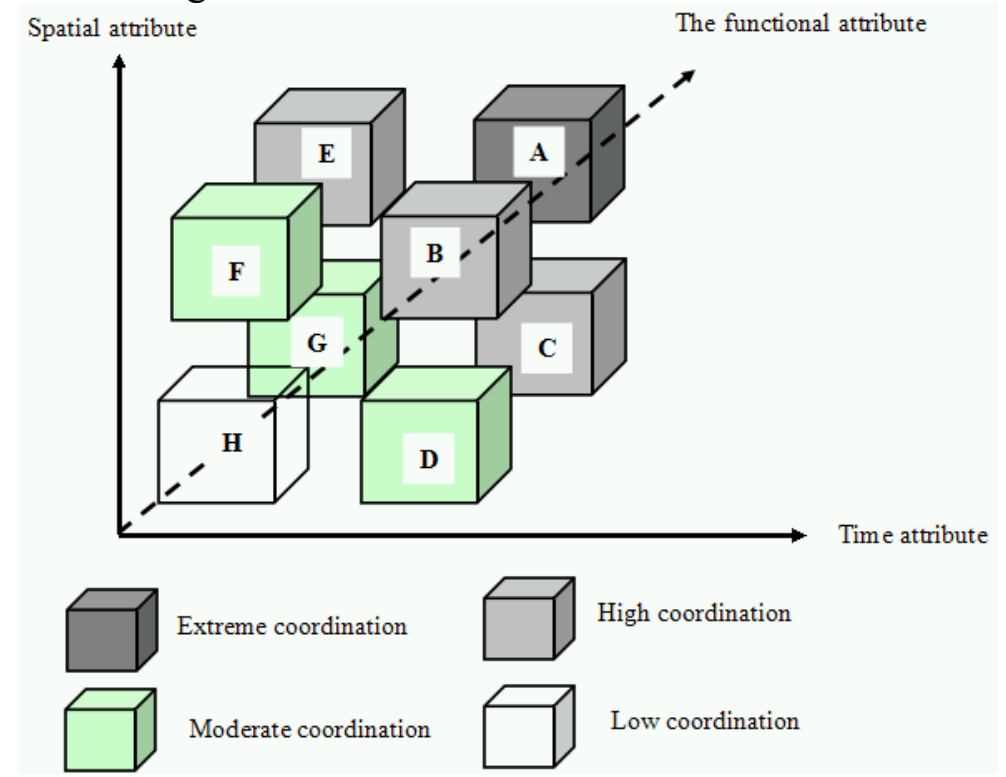

\subsection{The Principle of Construction}

Fig. 3 Tourism landscape image structure evaluation model

The construction of landscape in tourist areas must adhere to the strategy of sustainable development, building forest under the condition of the optimization of the construction of ecological landscape forest is the top priority of the construction, which is also the basis of creating the best natural visual field for the tourism objects. We must develop the ecological and economic benefits in both hands, so as to establish a comprehensive and reasonable forest ecosystem. Forest landscape ecology optimization reform must be closely linked to the principle of suiting place and trees, take the complex storied building into consideration, so as to strive for creating a long-term high quality landscape effect in the shortest possible time.

\subsection{The Selection of Tree Species}

The tree species in the tourist area should be chosen to be suitable for the region. In general, the native tree species are the best choice because it can have the best adaptability with the feature of anti-pest, which can own the local characteristics. Secondly, it can also introduce some foreign tree species to change the main area of the landscape tree species to optimize and reform the main area, so as to form their own characteristics. According to the local potential natural vegetation types to 
determine the species, choosing the species and the dominant species of shrub layer, meanwhile it can protect the existed landscape quality, expanding the diversity of the tree species, taking it as the species source of landscape optimization reform.

\subsection{Plant Configuration}

Plant configuration can play an important role in the construction of landscape forest. Plant configuration is an important basis for enhancing the landscape function, promoting the ecological function of plant and improving the adaptability of tree species. Moreover, the reasonable collocation of trees, shrubs, vines and herbs can play the full role of the plant color, shape, lines, and other natural beauty, thus, people can appreciate the beautiful and appreciating landscape, so as to create and enhance the effect of landscape.

\subsection{Transformation Model}

Through artificial activities, it can promote the transformation of forest, so as to give the different position for each scenic spots, beautify the forest, adjust tree structure, and improve the forest landscape value and ecological function, so as to create a distinctive beautiful forest landscape. In addition, we should excavate the cultural connotation of different regions, so as to build up the characteristic scenic spots according to the different needs of tourists.

\section{Reference}

[1]Chen P, Kerstetter D. 1999. International students' image of rural Pennsylvania as a travel destination. Journal of Travel Research, vol.37, pp: 256-266.

[2]Chon K-S. 1990. The role of destination image in tourism: A review and discussion. The Tourist Review, vol.45, pp: 2-9.

[3]Chon K-S. 1991. Tourism destination image modification process: Marketing implications. Tourism Management, vol.12, pp: 68-72.

[4]Echtner C, Ritchie J. 1991. The meaning and measurement of destination image. The Journal of Tourism Studies, vol.2, pp: 2-12.

[5]Baloglu S, McCleary K W. 1999. A model of destination image formation. Annals of Tourism Research, vol.26, pp: 868-897. 